\title{
Youth and Adolescents' Perceptions of Violence in Post-Apartheid South Africa: A Systematic Review of the Literature
}

\author{
Phadiel Hoosen $^{1}$ D $\cdot$ Sabirah Adams ${ }^{2}$ (D) $\cdot$ Habib Tiliouine $^{3}$ (D) Shazly Savahl ${ }^{1}$ (D)
}

Accepted: 26 November 2021 /Published online: 19 January 2022

(c) The Author(s), under exclusive licence to Springer Nature B.V. 2022

\begin{abstract}
The history of South Africa is embedded in violence. Exposure to various forms of violence is a consistent experience of children, adolescents, and young people in this context, negatively impacting various aspects of their lives and overall quality of life. However, these experiences of violence have been narrated from an adultcentric perspective. The current study thus aims to systematically review and synthesis existing empirical studies focusing on youth and adolescents' perceptions of violence in post-apartheid South Africa. We identified 34 articles that were included in the final review, with study samples ranging from youth and adolescents between the ages of 8 to 27-years-old. The included studies were delineated into three overarching themes using thematic analysis, namely: exposure to violence; gender and sexual-based violence; and interpersonal and school violence. We found several contributing factors that resulted in violence, such as: low socio-economic conditions, hegemonic masculinity, and male entitlement over women; which can be linked to the corollaries of apartheid. At a grassroots level, more research is needed to gain deeper knowledge about how youth and adolescents understand, conceptualise, and contextualise violence through various frameworks. Moreover, violence prevention and intervention requires a collaborative approach to exact meaningful change that will be beneficial for all stakeholders.
\end{abstract}

Keywords Youth · adolescents $\cdot$ perceptions $\cdot$ violence $\cdot$ safety $\cdot$ systematic review . post-apartheid South Africa

Shazly Savahl

ssavahl@uwc.ac.za

1 Centre for Interdisciplinary Studies of Children, Families and Society, University of the Western Cape, Cape Town, South Africa

2 Language Development Group, Academic Development Programme, Centre for Higher Education Development, University of Cape Town, Cape Town, South Africa

3 Faculty of Social Sciences, University of Oran, Es Senia, Algeria 


\section{Introduction}

The history of South Africa is embedded in violence. This can be traced to the arrival of the Dutch settlers in 1652, the Afrikaner-nationalist ideology of apartheid, and finally into the current dispensation of democracy. "Violence is any relation, process, or condition by which an individual or a group violates the physical, social, and/or psychological integrity of another person or group" (Bulhan, 1985, p.135). From this definition delineated by Bulhan (1985), violence is a profoundly negative process that impedes human growth, suppresses innate potential, limits productive development and self-actualisation, and causes death. With South Africa having one of the highest recorded rates of violent crime in the world, violence in the lives of youth and adolescents is ubiquitous - particularly amongst those living in low socio-economic status (SES) neighbourhoods (Hallman et al., 2015; Hamber, 2000). In some communities, youth and adolescents experience violence in a multi-layered social context. This includes violence in private and public settings, such as in the home, school, and neighbourhood (Savahl et al., 2019), and other spaces such as green spaces, shopping malls, and public transport (Sui et al., 2018). In 2008, the National Injury Mortality Surveillance System (NIMSS) in South Africa found violence to be the leading cause of death among 10to 19-year-olds (MRC-UNISA, 2010). The most recent statistics on violence against children from the South African Police Service (2020), indicate that between April 2019 and March 202042348 children were victims of contact crimes, including: 943 murders, 22070 sexual offences, 1137 incidents of attempted murder, 7506 incidents of assault [grievous bodily harm], and 10692 incidents of common assault. Further, 22070 children were victims of sexual offences, with: 17118 cases of rape, 3727 cases of sexual assault, 586 cases of attempted rape, and 639 cases of contact sexual offences. While a five-year trend analysis demonstrates that crimes against children has decreased by $6.4 \%$ from 2015/16 to 2019/2020 (South African Police Service, 2020 ), this only includes crimes reported to the police and not those since the first COVID-19 lockdown in the country. Thus, the threat of violence to the safety of adolescents and young people is of great concern within South Africa (Hallman et al., 2015).

Marginalised, disadvantaged, and previously oppressed South African population groups have experienced the imposition of violence since the documented landing of the first Dutch settlers (Boucher, 1991). The San and Khoikhoi were the first to experience the negative consequences of colonialism through forced dispossession of their lands by the invading 'White' settlers (Bredenkamp, 1991). These settlers were the cultural ancestors of the Afrikaner-nationalist ideology (Boucher, 1991), and from this lineage emerged the architects of apartheid that legislated severe oppression and violence into the rule of law. Studies have shown that exposure to violence may result in adverse psychological, emotional, and developmental challenges (Henrich et al., 2004). Consequences of violence include the 
manifestation of depressive symptoms, lower academic achievement over time, feeling less safe in a 'normally' safe environment, such as in schools (Henrich et al., 2004), a reduced sense of 'self' and well-being (Adams et al., 2017; Benninger \& Savahl, 2016; September \& Savahl, 2009), and a reduction in perceived hope (Oskin, 1996; Savahl et al., 2016). Given the paucity of empirical research studies exploring children's ${ }^{1}$, adolescents', and youths' subjective perspectives of violence, the need to understand and explore their perceptions of violence is of pressing concern (September \& Savahl, 2009).

A study by Shields et al. (2008) found substantial psychological distress resulting from experiences of violence among children, with exposure to all forms of violence disproportionately higher for older children than younger children. Similarly, Ward et al. (2001) found that children's exposure to multiple forms of violence indicate that they experience high levels of distress, as many do not have access to safe places. This was moderated by social support and family organisation and control. Gardner et al. (2015) revealed that sexual violence, and antisocial and violent behaviour was largely perpetrated by males associated with the traditional patriarchal system. Accordingly, the frequent exposure of youth and adolescents to violence and crime in their homes, schools, and communities contributes to antisocial behaviour. This creates exposure to violence across multiple domains, known as poly-victimisation (Finkelhor et al., 2007; Kaminer et al., 2013b). The high prevalence of polyvictimisation suggests that experientially, violence is an inescapable part of these youth and adolescents' daily lives (Kaminer et al., 2013b). A study by Scorgie et al. (2017) revealed that adolescent girls and boys encountered violence differently. Sexual harassment and violence were more prevalent among girls, while boys feared threats by local gangs, physical violence, and the potential to engage in substance use. For boys, homes were places of safety, while girls often experienced sexual violence, abuse, and neglect in the home. Although spaces traversed by youth and adolescents' was frequently marked by fear and violence, they show a remarkable capacity for resilience in navigating the ambivalence of seeing their neighbourhood as having both good and bad places (Scorgie et al., 2017). Resilience refers to an individual's ability to sustain 'normal' functioning following an adverse experience, which is influenced by biological, psychological, interpersonal, and socio-cultural factors (Ungar $\&$ Perry, 2012). However, in relation to the predisposition to violence, the capacity for resilience is not universal. Oskin (1996) explored the relationship between hope and community violence. For younger children, victimisation and hope agency had a negative correlation, while for older children it was positive. Gender differences in coping strategies may offer a partial explanation, as the effect is stronger in girls than boys at both ages (Oskin, 1996).

\footnotetext{
1 The term 'children' refers to every child between the ages of 0 to 17 years. This position is consistent in the United Nations Convention on the Rights of the Child (UNCRC), as well as the Constitution of South Africa wherein a child is defined as any individual between 0 and 18 years.
} 


\section{Rationale for the Review}

In South Africa, exposure to various forms of violence is a consistent experience of children and young people, negatively impacting various aspects of their lives and overall quality of life (Adams et al., 2019). However, we note that strategies to reduce the different forms of violence should be premised on the understanding that violence is a complex and dynamic concept, historically situated in colonialism and institutionalised racism. Further, the vertical violence experienced as a result of institutionalised racism is intergenerational. For this reason, it is important to foreground the systemic nature of violence and how it has become embedded in the daily lives of South African people (Ramphele, 1997). Administrative data have demonstrated the extent and impact of violence on the lives of young people (see e.g., Statistics South Africa, Victims of the Crime Survey, 2020). However, if we hope to gain a complete picture of the impact of violence on young people lives, we need both objective indicators and subjective data. Therefore, we need to engage directly with young people to complement the objective data, which would allow for a more comprehensive understanding of how young people negotiate, make sense of, and construct their understandings of violence (Savahl et al., 2019). While this shift toward the subjective is evident in the scientific literature, it has not filtered into strategies for programmes and policy-making. From an evidence-based perspective, it is critical that a synthesis of the scientific research on young people's subjective perspectives and experiences of violence is conducted. This provides the key rationale for the current review. A systematic review of the literature is essential as it provides a more nuanced understanding of how violence impacts young people's lives. Moreover, it affords a critical synthesis of the current state of the available research on the topic. This could potentially inform prevention and intervention efforts, guide policies, legislation, appropriation, and oversight, with the aim of improving young people's quality of life (Savahl et al., 2019).

\subsection{Aim of the Study}

The aim of the study was to systematically review existing empirical studies and synthesise the findings regarding youth and adolescents' perceptions of violence in post-apartheid South Africa.

\section{Method}

\subsection{Review Question}

How do youth and adolescents perceive violence in post-apartheid South Africa? 


\subsection{Design}

We employed a systematic review that focused on empirical peer-reviewed literature. The aim of a systematic review is to appraise and highlight the key concepts and provide exhaustive summaries of available literature, reinforcing a research area, main sources, and types of evidence available (Khan et al., 2003). The SPIDER (Sample, Phenomena of Interest, Design, Evaluation, Research type) was used to develop the review question for the study and informed the search strategy. We utilised the PRISMA Statement to conduct the review (Moher et al., 2015).

\subsection{Article Search}

We conducted a comprehensive search between May and September 2019 across the EBSCOhost, Google Scholar, JSTOR, and ScienceDirect meta-databases, for peerreviewed journal articles published in English from the year 1994 until 2019. The keywords used in the defined database searches were: youth; adolescents; perceptions; violence; systematic review; post-apartheid; South Africa; and safety.

\subsection{Inclusion and Exclusion Criteria}

We included articles that explored youth and adolescents' subjective perceptions of violence in South Africa; studies conducted from between 1994 to 2019; qualitative, quantitative, and mixed-methods studies; and studies published in English. The current study defined youth and adolescents as any persons up to and including the age of 25 years. Studies were excluded if: the study participants were older than 25-years of age; not conducted in South Africa; conducted outside the timeframe of 1994 to 2019; and studies employing adults as proxies for exploring youth and adolescents' perspectives. All relevant studies yielded from the database searches were available through the University of the Western Cape (UWC) Library subscription or were publicly available. Reference mining (the process of reviewing the reference list of included studies) was used to access studies not yielded by the initial database searches.

\subsection{Quality Appraisal}

We used an adapted version of the Evaluation Tool for Quantitative and Qualitative Research Studies (Long et al., 2002; Long \& Godfrey, 2004) to critically appraise identified studies for inclusion (Long et al., 2002). The review areas common to both tools, and applicable to both qualitative and quantitative studies, were used, namely: study overview, study setting, sample, ethics, and policy and practice implications. The tool was further adapted for use with mixed-methods studies, and we were able to make evaluative comments regarding the strengths and weaknesses of each study rather than the use of scoring, to include or exclude a study. 


\subsection{Data Extraction}

We used an adapted data extraction table to extract information from the included studies. The table included the following key areas: Authors; Context; Content - Aims and Objectives; Method and Data analysis; Sample size and age cohort; and Key findings. The data extraction tables for the three study themes are available as 'Supplementary materials' for this article.

\subsection{Data Synthesis}

We employed a narrative synthesis in this review. This encompassed the summary of the key findings (Arai et al., 2007), and afforded a 'textual approach' to 'tell the story' (Popay et al. 2006) of the results from the included studies. This synthesis technique affords a comprehensive understanding of the study by developing a preliminary synthesis, exploring similarities and relations in the data, and assessing the robustness of the synthesis product (Popay et al. 2006; Arai et al., 2007).

\subsection{Procedure and Ethics}

The primary author conducted the database searches and extracted the data, which was confirmed by co-authors to reach consensus. This was done through each author appraising and reviewing each article identified for inclusion and was important to verify the findings and minimize bias to ensure accuracy of results and findings (Leibovici \& Reeves, 2005). The specified database searches were accessed through the UWC Library. All references obtained through the review were cited in full, with clear acknowledgement of the respective authors. Ethics clearance was obtained from the Humanities and Social Sciences Research Ethics Committee of the UWC. Finally, the UWC is acknowledged as the institutional resource that enabled the review to be completed.

\section{Results}

The articles included in the review were categorised into three themes based on the study focus, namely:

- Theme 1: Exposure to violence

- Theme 2: Gender and sexual-based violence

- Theme 3: Interpersonal and school violence

The studies included in the review were synthesised and are discussed under the key headings of: Content - aims and objectives; Method and data analysis; Sample size and age cohort; and Key findings. 


\subsection{Article Search Procedure}

The keyword searches provided the following results: EBSCOhost, $n=32$; Google Scholar, $n=112$; JSTOR, $n=74$; and Science Direct, $n=61$, totalling 279 articles. Of the 279 articles, 92 were included for abstract appraisal. Thereafter, 29 articles were included for full-text appraisal and subsequently included in the review. Reference mining was then conducted on the 29 articles, which yielded a further 178 articles. Of the 178 articles, only five articles were included in the review based on reference mining. Figure 1 below presents the PRISMA Statement flow diagram in selecting the 34 articles for review.

\subsection{Research Context}

The 34 studies included in the review were conducted across various provinces of South Africa. The majority of the studies were conducted in low SES, peri-urban
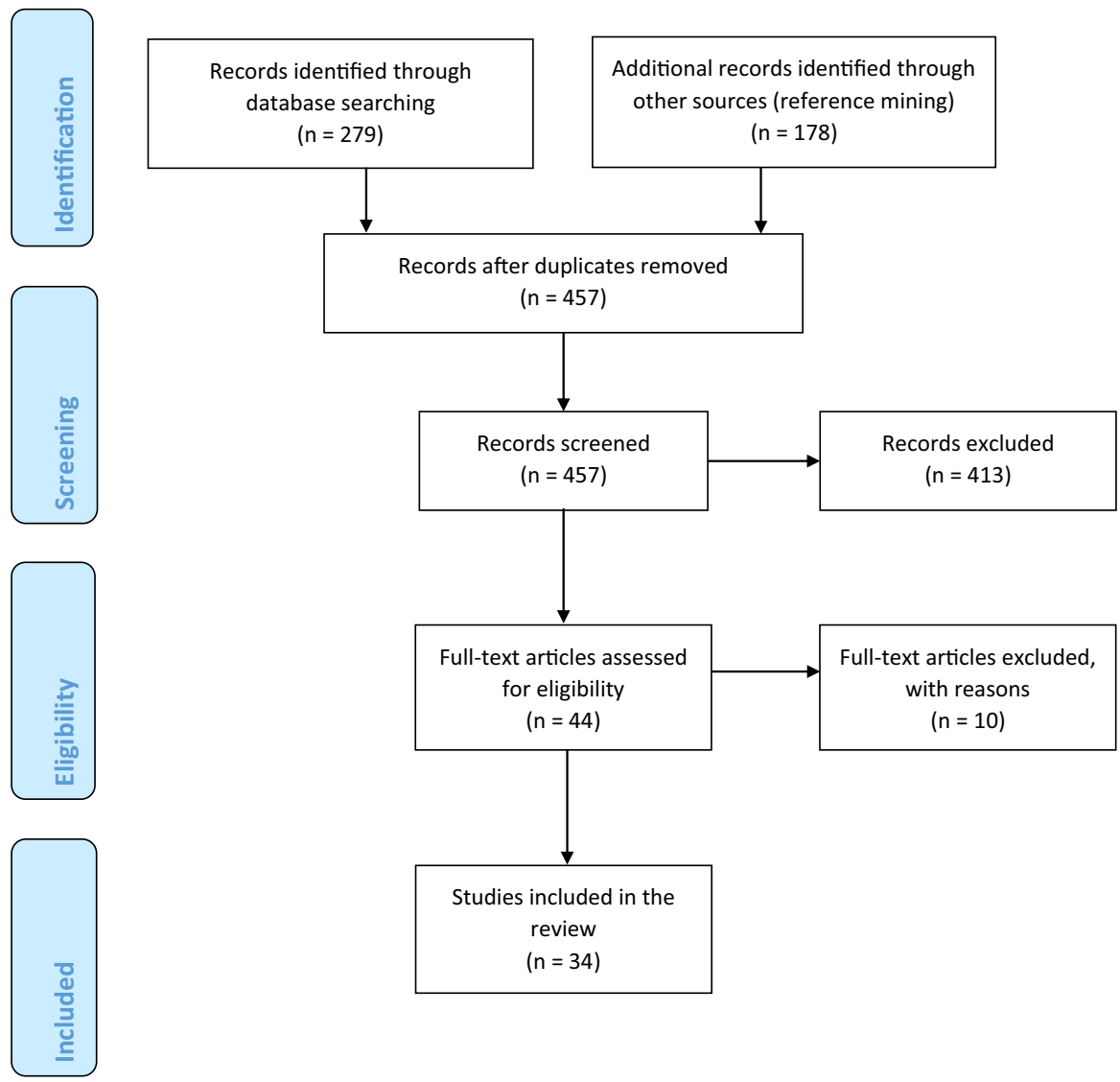

Fig. 1 Review process (PRISMA, 2009) flow diagram 
township communities (the term township refers to the underdeveloped racially segregated urban areas that, under the apartheid rule, were delineated for people who were classified as 'Black', which broadly refers to those classified as 'Black', 'Coloured', and 'Indian), with fewer studies in urban and rural areas. Most of the research participants were youth and adolescents attending primary and secondary school, with two studies conducted within a university and a community health centre.

\subsection{Themes}

\subsubsection{Theme 1: Exposure to Violence}

This theme includes 10 of the 34 articles focusing on adolescents' and youth exposure to violence. 'Exposure to violence' refers to both experiences of and witnessing violence (World Health Organization, 2019).

\subsubsection{Content: Aims and Objectives}

Among the foci in this theme, Selenga and Jooste (2015) explored the experiences of youth victims of physical violence attending a community health centre on the Cape Flats. Swartz and Scott (2014) explored the settings, forms, and experiences of violence amongst a sample of 37 'Black' youth living in an impoverished township in Cape Town. Shields et al. (2009) compared the effects of witnessing school or neighbourhood violence and victimisation on psychological distress. The study by Meinck et al. (2017) investigated whether children know about post-abuse services, if they disclose and seek services, and the outcomes of help-seeking behaviour. Ward et al. (2001) aimed to establish the prevalence and relationship between adolescents' exposure to violence and related symptoms in the South African context. The study by Kaminer et al. (2013a) aimed to establish gender patterns in the independent and comparative contributions of five types of violence exposure to the severity of post-traumatic stress symptoms among isiXhosa-speaking South African adolescents. Du Plessis et al. (2015) examined the contribution of different forms of violence to internalising and externalising symptoms among young adolescents in South Africa. Ramphele (1997) examined the nature of violence as experienced by 'Black' African adolescents. The study by Wood et al. (1998) explored aspects of sexual dynamics occurring within adolescent relationships. Kaminer et al. (2013b) aimed to establish the prevalence of lifetime exposure to different types of violence

\footnotetext{
2 The racial groups, that is 'Coloured', 'Black', and 'Indian', were employed as racial categories within the apartheid era to reinforce a segregated society and refer to those who were not afforded the same benefits as 'Whites' in this era. These terms are used here solely for descriptive purposes and does not imply endorsement of these terms by the author (Adams et al., 2017).
} 
in the home, school, and community, as well as the prevalence of poly-victimisation across multiple contexts.

\subsubsection{Method and Data Analysis}

More studies used quantitative methods $(n=6)$ than qualitative methods $(n=$ 4) within this theme. Shields et al. (2009) conducted a study using a quantitative approach, and descriptive statistics and regression analysis. Meinck et al. (2017) used a quantitative, community-based household survey and descriptive analyses. Ward et al. (2001) conducted a quantitative study using Spearman-rank correlations to analyse the data. Kaminer et al. (2013a) used Pearson product-moment correlation, and multiple linear regression analysis. Du Plessis et al. (2015) utilised a quantitative approach and analysed data using Pearson product-moment correlation and descriptive statistics. Selenga and Jooste (2015) used a qualitative methodological framework within a phenomenological, exploratory, descriptive, and contextual design. Swartz and Scott (2014) used inductive coding to analyse data. Two theories were employed by studies within this theme namely, the notion of 'moral capital', and ideas of 'gratuitous violence' and 'increasing barbarism and lawlessness' (see Hobsbawm, 1998). Ramphele (1997) conducted a qualitative study using an action research approach by utilising surveys, interviews, workshops, and participant observation. Wood et al. (1998) used a qualitative approach and a case-control study. Kaminer et al. (2013b) employed a quantitative method, using descriptive statistics and Spearman Rank-order correlation to analyse the data.

\subsubsection{Sample Size and Age Cohort}

Of the 10 articles in this theme, nine had a sample size of less than 1000 participants. The study by Meinck et al. (2017) was the only one to include more than 1000 participants, with a sample of 3515 adolescents between the ages of 10- and 17-years. The study by Kaminer et al. (2013b) included a sample of 617 adolescents (female, $n=336$; male, $n=279$ ) aged between 12 to 15 -years. Du Plessis et al.'s (2015) study included 616 adolescents (54.6\% female and $45.4 \%$ male) aged 12 - to 15-years. Shields et al. (2009) used a sample of 247 learners, aged 8- to 13-years. The study by Kaminer et al. (2013a) included 230 learners (138 females and 92 males), aged 14 to 21-years. Ward et al. (2001) included 104 adolescents (female, $n=32$; males, $n=71$ ), aged 17-years. The study by Ramphele (1997) included 48 adolescents, aged 10 to 14-years. Swartz and Scott (2014) included a sample of 37 youth, aged 14 to 20-years. The study by Wood et al. (1998) included a sample of 24 pregnant adolescent women, aged 14 to 18-years. Selenga and Jooste (2015) including eight male participants between the ages of 18 to 27-years in their study.

\subsubsection{Key Findings}

The findings in this theme related to the psychological effects that violence has on an individual. Selenga and Jooste (2015) found that some participants could cope through social support, while others experienced symptoms such as aggression, 
anxiety, and depression, making youth more likely to participate in gang activities. The findings by Shields et al. (2009) suggested that school victimisation had a stronger effect on distress and psychological well-being than witnessing violence, however, the opposite was found in the neighbourhood. The results by Ward et al. (2001) indicated that most children were exposed to at least one type of violence, which made them more vulnerable to experience other types of violence. PTSD and depression symptoms appeared related to most types of violence exposure, with anxiety symptoms only found when violence was perpetrated in the home or by someone known to the child. Kaminer et al. (2013a) found that the most common form of violence exposure was witnessing community violence. Increased exposure to community and sexual victimisation were associated with symptom severity among girls, while direct victimisation in both the community and domestic settings were associated with symptom severity in boys. The findings by du Plessis et al. (2015) demonstrate that domestic victimisation was the strongest predictor of both internalising and externalising challenges. Moreover, cumulative exposure to other forms of violence contributed to the manifestation of aggression and conduct disorder, but not depression. Kaminer et al. (2013b) found that exposure to violence across multiple life domains is part of daily life for younger adolescents, with access to safe spaces limited.

Swartz and Scott (2014) argue that having rules did not mitigate violent behaviour in society. However, rules can be a social asset that reflect young people's rational decision-making ability despite adverse contexts. The findings by Meinck (2017) suggest that most children knew about victim abuse services. However, only $20 \%$ of abused children disclosed their abuse or requested help. Most children disclosed to a caregiver, teacher, or family member rather than professionals. Ramphele (1997) found that violence occurred in the home, school, and community, and highlighted the role of resilience. Wood et al. (1998) found that violence was a consistent feature of sexual relationships that enforced male control and defined sexual intercourse.

\subsection{Theme 2: Gender and Sexual-Based Violence}

The eight articles in this theme focused on gender and sexual-based violence.

\subsubsection{Content: Aims and Objectives}

The studies in this theme centred on understandings and experiences of gender and sexual-based violence by female and male victims, and perpetrators. Mosavel et al. (2011) sought to examine the barriers that affect the health and well-being of youth, toward developing a health promotion program. Heeralal (2014) conducted a study to describe the direction and intensity of adolescents' perceptions of rape. Rasool (2017) aimed to describe adolescents' experiences of gender-based violence (GBV). Gordon and Collins (2013) explored how women's identities and social interactions were shaped by GBV in their communities, and in higher education institutions. Petersen et al. (2005) explored the multiple levels of risk that make adolescent girls vulnerable to sexual violence. Sathiparsad (2005) examined males' perspectives on 
gender roles and violence in relationships. Richter et al. (2018) explored the personal and social vulnerability of male sexual abuse victims, and mental health outcomes in South Africa. Haffejee (2006) explored adolescent girls' experiences of GBV in relationships, their constructions of gender violence, and perspectives on interventions.

\subsubsection{Method and Data Analysis}

In this theme, five studies utilised qualitative methods and three used quantitative methods. The qualitative study by Mosavel et al. (2011) employed grounded theory analysis (see Glaser \& Strauss, 1965) using an inductive process. Heeralal (2014) employed a quantitative, descriptive survey research design using descriptive and inferential data analysis. Rasool (2017) used a quantitative approach, and descriptive analysis. The qualitative study by Gordon and Collins (2013) used social constructionism and applied discourse analysis to the data. Petersen et al. (2005) conducted a qualitative rapid focus ethnographic study using an inductive thematic analysis. Sathiparsad (2005) employed a qualitative descriptive research method and framework employing focus group interviews, and used thematic analysis to analyse data. Richter et al. (2018) utilised a quantitative, longitudinal research design, using descriptive statistics and multiple linear regression analysis. Haffejee (2006) used a qualitative, explorative research method. Data were collected through focus group discussions and analysed using content analysis.

\subsubsection{Sample Size and Age Cohort}

The studies by Rasool (2017) and Richter et al. (2018) had a sample size over 1000 participants. Rasool (2017) included 3958 adolescents $(n=1756$ in 2012; $n=2202$ in 2013) in Grade 8, aged 13- to 15-years. Richter et al. (2018) included 2000 male participants, aged 22 to 23-years. Three studies included sample sizes of more than 100 participants. Heeralal (2014) included 347 Grade 11 learners (200 females; 147 males); Haffejee (2006) included 140 girls aged between 1-3 and 17-years; and Mosavel et al. (2011) included 112 adolescents with a mean age of 15-years. The studies by Gordon and Collins (2013, $n=12$ female residence students), Sathiparsad (2005, $n=10$ isiZulu-speaking males), and Petersen et al. (2005) used smaller samples (five male and five female adolescent focus groups) with participants between the ages of: 19 to 23-years (Gordon \& Collins, 2013); 15 to 24-years (Sathiparsad, 2005); and 13 to 16-years (Petersen et al., 2005).

\subsubsection{Key Findings}

The findings of the studies in this theme focused on rape and fear. Heeralal (2014) found significant differences between males and females perceptions' of rape, specifically related to the punishment of offenders, the motivation for rape, and whether rape is a degrading act that decreases women's self-esteem. Adolescents expressed that they were aware that rape is unlawful and that effective law enforcement can reduce rape. The participants did not think that the culture of violence contributed to rape, or that 
women are reluctant to report being raped. Further, they considered rape to be a crime of aggression that decreases self-esteem (Heeralal, 2014). Rasool (2017) found high levels of GBV among adolescents, with boys more likely to report experiencing all types of GBV than girls. Incidence of rape was found to be between 8 and 11\%, with most perpetrators being male. Adolescents were more likely to report experiences of violence to family and friends, rather than authorities. Although a quarter of perpetrators were strangers, most were known to the victims (Rasool, 2017). Petersen et al. (2005) found multiple levels of risk factors for adolescent girls and boys to become either victims or perpetrators of sexual violence. At the distal socio-cultural/environmental level, factors included normalisation of interpersonal violence, traditional beliefs of masculinity, poverty, and casual sexual encounters; leading to a rape-supportive culture. At the proximal-situation-context/social normative level, factors converged to weaken adult and community protective factors and lower social support, which leads to high-risk social norms. At the intrapersonal level, factors included low selfefficacy, low self-esteem, and interpersonal affective anger (Petersen et al., 2005). Richter et al. (2018) focused on reports of all sexual activity, and found that it increased with age, whereas most sexual coercion decreased after the age of 18-years. For adolescents aged 11-years, most sexual activity was coerced. The highest rates of coercion occurred between ages 13 - and 14-years, with $45 \%$ of coerced touching at age 14 -years, $41 \%$ of coerced oral sex at age 13-years, and $31 \%$ of coerced penetrative sex at age 14-years (Richter et al., 2018). Gordon and Collins (2013) found that the fear of becoming a victim of GBV restricted the daily activities of women. Several discourses that act to normalise, legitimise, and excuse GBV, creates a culture of fear for women on a higher education institution campus. Thus women's lives were structured by the fear of GBV and negatively impacted as a result (Gordon \& Collins, 2013). The findings by Sathiparsad (2005) showed that the participants perceive transitional love, transactional sex, forced sex, violence, the objectification of women, and multiple partnerships as acceptable elements of heterosexual relationships, with youth uncertain about what constitutes a 'good' relationship. Haffejee (2006) found GBV and male hegemony to be a common feature in relationships, with school not considered a safe place; making it difficult for young women to challenge the status quo. Mosavel et al. (2011) suggest that health promotion programs should create safe spaces for youth to critically question the assumptions and manifestations of a patriarchal society, with a need for multi-sectoral interventions directed at many levels to prevent GBV.

\subsection{Theme 3: Interpersonal and School Violence}

This theme comprises 16 articles that focused on interpersonal and school violence.

\subsubsection{Content: Aims and Objectives}

Khan et al. (2016) explored adolescents' perceptions of substance use as a contributing factor to community violence. Kubeka (2008) explored 'Black' adolescents' experiences and perceptions of domestic violence in their homes and in intimate relationships. Scorgie et al. (2017) explored how interpersonal violence 
was experienced differently by boys and girls, how they conceptualise 'dangerous' and 'safe' spaces in their neighbourhood, and what gaps exist in available services for youth in Hillbrow. Manyema et al. (2018) investigated the association between interpersonal violence and psychological distress among rural and urban young women. Petersen et al. (2017) explored the self-identity constructions of South African adolescents with a history of family violence. Isaacs and Savahl (2014) explored the sense of hope in adolescents living in communities with high levels of violence. Mampane (2014) examined adolescents' conceptualisation of school violence in a rural secondary school. Burnett (1998) aimed to understand schoolrelated violence experienced by adolescents in the context of chronic poverty in a South African community. Shields et al. (2008) investigated the relationship between exposure to community violence (neighbourhood, school, police, and gang violence) and psychological distress, and to identify moderating and mediating variables between exposure to community violence and psychological distress. Savahl et al. (2013) explored the relationship between exposure to community violence, hope, and well-being and examined whether hope is a stronger predictor of well-being than exposure to violence. Hallman et al. (2015) compared adolescents' perceptions at two different stages of development: pre-adolescence (grade 5) and early-to-mid-adolescence (grades 8 and 9). Ncontsa and Shumba (2013) investigated the nature, causes, and effects of school violence in four South African secondary schools. Parkes (2007a) examined how young people living in a violent neighbourhood construct understandings about danger, violence, and safety. Ngqela and Lewis (2012) focused on adolescents' experiences of school violence in a township in order to understand the phenomenon, and inform school prevention and/or intervention strategies. Parkes (2007b) explored children's understandings of violence in their neighbourhood. Neser (2006) explored students' experience as victims of aggressive acts.

\subsubsection{Method and Data Analysis}

Among the studies in this theme, 10 used qualitative methods, four used quantitative methods, and two used a mixed-methods approach. Khan et al. (2016) employed a qualitative framework, using Braun and Clarke's (2006) theoretical thematic analysis technique. A qualitative, phenomenological study, conducted by Kubeka (2008), employed Denzin's (1989) interpretive analysis. Scorgie et al. (2017) used a qualitative method, with an inductive thematic analysis approach. Manyema et al. (2018) conducted a quantitative study, and analysed the data using generalised structural equation models. Petersen et al. (2017) conducted a qualitative study, with data thematically analysed using guidelines by Vaismoradi et al. (2013), and Braun and Clarke (2006). Isaacs and Savahl (2014) used a qualitative framework with an exploratory approach, using theoretical thematic data analysis. Mampane et al. (2014) conducted a qualitative study using a constructivist grounded theory approach (Charmaz, 2006) and thematic data analysis (Braun \& Clarke, 2006). Burnett (1998) used a mixed-methods design, utilising a deductive approach and descriptive statistics to analyse data. The study by Ncontsa and Shumba (2013) used a sequential mixedmethods approach, with quantitative data analysed using descriptive statistics and 
qualitative data analysed using thematic analysis. Shields et al. (2008) employed a quantitative framework, using descriptive statistics, pairwise correlation, and regression data analysis. Neser (2006) conducted a quantitative study, using descriptive statistics and chi-square tests. Savahl et al. (2013) utilised a quantitative approach using descriptive statistics, Pearson correlations, and multiple regression to analyse the data. The study by Hallman et al. (2015) employed a qualitative method and a deductive approach was used to collate and analyse data. Parkes (2007a) conducted a qualitative study using thematic data analysis. A qualitative research study was conducted by Ngqela and Lewis (2012), using thematic data analysis. Parkes (2007b) employed a qualitative method and used thematic data analysis.

\subsubsection{Sample Size and Age Cohort}

The studies in this theme included relatively small sample sizes compared to Themes 1 and 2. Neser (2006) used the largest sample of 995 students, comprising 453 females and 542 males, with 602 learners younger than 14-years and 393 older than 14-years. Manyema et al. (2018) included 926 young women aged 18 to 22-years. Savahl et al. (2013) conducted a study with 566 adolescents aged between 14 to 17-years. Shields et al. (2008) included 185 participants aged 8 to 13 -years in their study. Hallman et al. (2015) conducted a study with 136 primary school students in one urban and one rural community. The study by Ncontsa and Shumba (2013) included 80 students from four secondary schools (no ages were recorded). Burnett (1998) conducted a study with 76 adolescents in Grade 9 (no ages were recorded). Scorgie et al. (2017) used data collected in the formative phase of the WAVE study with 59 adolescents aged 15- to 19-years. In two articles by Parkes (2007a, b), the study samples included 36 participants focusing on six friendship groups in three age cohorts of 7-8-years, 9-10-years, and 12-13-years. Kubeka (2008) conducted a study with 23 adolescent boys and girls aged between 14 and 20-years old. Khan et al.'s (2016) study included nine female and seven male secondary school adolescents aged between 15- and 16-years. The study by Isaacs and Savahl (2014) included eight female and six male participants aged between 14- and 15-years old. Ngqela and Lewis' (2012) study sample included 13 adolescent learners (no ages were recorded). Petersen et al. (2017) included one male and 11 female participants aged 15- to 18-years. Mampane et al. (2014) recruited five and four male participants aged 15- to 17-years.

\subsubsection{Key Findings}

The key findings across the articles included in this theme relate to hope, safety, coping, and resilience. The study by Isaacs and Savahl (2014) found that hope was related to religion and faith. Hopelessness was associated with negative effects stemming from exposure to community violence. Hope was perceived as a useful motivational tool in goal setting and future-planning (Isaacs \& Savahl, 2014). Savahl et al. (2013) found a positive relationship between children's hope and their well-being. Exposure to community violence and hope were significant predictors of wellbeing. Hope emerged as a stronger predictor of child well-being than exposure to 
community violence (Savahl et al., 2013). Parkes (2007a) identified young people's attempts to stay safe through reliance on adult protection, avoidance and escape, peer support and retaliation. Hallman et al. (2015) found that relative to Grade 5 students, wide gender differences were found in access to the public sphere among students in grades 8-9; with girls' mobility more restricted than boys limiting opportunities for further development. Parkes (2007b) found that violence carried multiple meanings and multiple consequences for children striving to make sense of their experiences. As violence was a constant threat in their neighbourhood, some children resisted violent practices whilst others perpetuated it (Parkes, 2007b).

Shields et al. (2008) found that exposure to all forms of violence resulted in psychological distress. Hearing about violence from others had almost the same effect as witnessing it. Perceived safety offered by social support, family organisation, and family control reduced the effects of exposure to certain kinds of violence (Shields et al., 2008). Petersen et al. (2017) found that adolescents' self-identities in the context of family violence were characterised by polarities of love versus hate, protect versus blame, and compassion versus anger and resentment. The adolescents also self-defined in terms of coping and resilience, despite elevated risks of self-harm behaviour (Petersen et al., 2017). The results by Mampane et al. (2014) indicated that adolescents view school violence both as negative (it causes harm), and positive (it serves a strategy to ensure order and protection). Violence was conceptualised as interweaving constructs of power, discipline, and aggression. Ncontsa and Shumba (2013) found that bullying, vandalism, gangsterism, lack of discipline, intolerance, and corporal punishment were prevalent in schools, resulting in loss of concentration, poor academic performance, absence from class, and depression.

The findings by Neser (2006) showed that school violence was a reality in children's lives, with $40 \%$ of victims frequently exposed to violence. Most victims were subjected to verbal aggression, physical aggression, and incidents of relational aggression (social exclusion). Male learners were found to initiate $60 \%$ of aggressive incidents. Ngqela and Lewis (2012) concluded that school violence is a multifaceted phenomenon with unique contextual characteristics, with educators showing a lack of adequate classroom management skills, highlighting a need for it to be enhanced within this community. Manyema et al. (2018) found that the relationship between violence and psychological distress differs between women in urban and rural contexts. It was found to be influenced by individual, household, and community (contextual) factors. Additionally, experiences of interpersonal violence were higher in urban than rural young women, and was not found to be associated with psychological distress in rural young women.

Kubeka (2008) found that observational learning contributes to PTSD and dating violence among adolescents. The intergenerational transmission of violence was evident in the 'participants' experiences and perceptions of violence within their own relationships. There was also evidence of socialised male power and control, where violence was used to affirm masculinity. In the article by Scorgie et al. (2017), both girls and boys reported high exposure to witnessing violence and crime. For girls, the threat of sexual harassment and violence was pervasive, while boys feared local gangs, the threat of physical violence, and substance use. While home was predominantly a safe space for boys, girls often experienced sexual violence, abuse, and neglect within the home. Some adolescents developed coping mechanisms, such as 
actively seeking out community theatres, churches, and other places of refuge from violence. Khan et al. (2016) found that adolescents perceived violence to be rooted within gang culture as well as the involvement in shared markets for illicit substance trading. Burnett (1998) found that the ideology and structures of apartheid exposed children to a context of impoverishment and structural violence. Further, school subjected children to structural, psychological, and physical violence daily, with violent behaviour or discipline justified as an effective teaching practice by authoritarian parents and teachers.

\section{Discussion}

This study aimed to systematically review and synthesise existing empirical research examining how youth and adolescents perceive violence in post-apartheid South Africa. The keyword searches and reference mining yielded 457 articles, of which 34 were included in the review. The articles included in this review confirmed a paucity of empirical work in this area in South Africa, with over $60 \%$ of research conducted in the last decade. The articles focused on three themes: exposure to violence; gender and sexual-based violence; and interpersonal and school violence. The most important and prominent implication that emerged from the review was that violence occurs in multiple settings, such as the home, school, neighbourhood (community), and within social relationships. Those exposed to violence were at risk of psychiatric and psychological challenges, difficulty with interpersonal relationships (Hertweck et al., 2010), negative internalising and externalising behavioural problems (Ward et al., 2001), and poor standards of living (Savahl et al., 2017). Female adolescents were especially vulnerable to culturally and socially sanctioned male hegemonic GBV (Gordon \& Collins, 2013), influenced by the legacy of apartheid (Campbell, 1992). This cycle of violence has become a prominent feature in schools, perpetuated by adolescents and educators alike (Ncontsa \& Shumba, 2013).

The reviewed studies were conducted across the nine provinces of South Africa. Most of the studies were conducted in urban and peri-urban (township) areas within the Western Cape, while the remainder were conducted in KwaZuluNatal, Mpumalanga, and the Eastern Cape, in rural and semi-rural areas. Three studies in particular were conducted across both urban and rural areas, namely the study by Meinck et al. (2017) (Western Cape and Mpumalanga provinces), Hallman et al. (2015) in a peri-urban and rural community in KwaZulu-Natal, and Manyema et al. (2018) at a rural site in Mpumalanga and an urban site in Soweto, Gauteng.

In terms of methodological frameworks, the reviewed studies used qualitative, quantitative, and mixed-methods approaches, with most studies utilising a qualitative framework (see Supplementary Tables), and fewer utilising a mixedmethods framework. Qualitative studies by Heeralal (2014), Hallman et al. (2015), and Mosavel et al. (2011) had sample sizes of over 100 participants; Meinck et al. (2017), Rasool (2017), and Richter et al. (2018) had sample sizes of over 2000 participants using quantitative studies; and Burnett (1998) and Ncontsa and Shumba 
(2013) had sample sizes of under 90 participants. As most studies used qualitative research frameworks, the data analysis technique most often used was inductive thematic analysis (Isaacs \& Savahl, 2014; Khan et al., 2016; Ngqela \& Lewis, 2012; Parkes, 2007a, b; Petersen et al., 2005; Petersen et al., 2017; Scorgie et al., 2017). Participants in the various studies were selected from the general population in the researched communities. The participants from the quantitative studies were reported to be a representation of the population of the specific studies. The majority were adolescent male and female students selected from primary and secondary schools, while the study by Gordon and Collins (2013) included university students. The age range of the participants in the reviewed studies were youth and adolescents between 8- and 27-years old. The most prominent age cohort studied was 14- to 17 -year olds. For the current review, youth and adolescents were defined as any persons up to and including the age of 25. However, the article by Selenga and Jooste (2015) included eight participants aged 18- to 27-years. Despite the ages of the participants being slightly older than the defined age range, the study was retained as it offered relevant qualitative information about the youth victims' experiences of and exposure to physical violence in Mitchells Plain on the Cape Flats, in the Western Cape Province.

In terms of theory, only one third of the reviewed articles used a theoretical framework to formulate their studies. The theories used in the studies included: Social Constructionist theory; the Theory of Moral Capital; Grounded Theory; the Theory of Triadic Influence; Actor Network Theory; Hope Theory; Goldstein's Tripartite Conceptual Framework; Trauma Theory; Social Learning Theory; and Bio-ecological Theory. The application of theory served to highlight contextual experiences and understandings of adolescents and youth concerning exposure and experiences of violence.

The following section further explores the three themes that emerged from the study, namely exposure to violence, gender and sexual-based violence, and interpersonal and school violence.

\subsection{Exposure to Violence}

The key findings of the studies in this theme indicate that children, adolescents, and youth who witnessed, were exposed to, and directly experienced violence were at an increased risk for short-term and long-term physical and mental health challenges (du Plessis et al., 2015; Kaminer et al., 2013a, b; Selenga \& Jooste, 2015; Shields et al., 2009; Ward et al., 2001). The experience of violence was shown to affect participants' interpersonal relationships, as they could become the victim or perpetrator of violence, with the risk of psychopathology higher among this cohort (Hertweck, et al., 2010). Those who experienced violence displayed internalising behaviours such as depression, anxiety, and PTSD as well as externalising behaviours such as poor school performance, and conduct disorder such as bullying, vandalism, and physical aggression towards others. Without appropriate intervention, undiagnosed 
and untreated internalising and externalising problems markedly hinder functioning in later life (Ward et al., 2001), and overall quality of life (Savahl et al., 2017).

Parental responses to and engagement with experiences of violence influences adolescent's developmental outcomes (Ramphele, 1997). For this reason, it is not surprising that violence in the home poses the greatest risk for developing internalising and externalising behaviours in adolescence (du Plessis et al., 2015). The home and family network should be spaces of safety for adolescents to receive nurturance (Carr, 1999) and protection by adults/guardians from external dangerous threats in their community (Parkes, 2007a). However, when safety within the home environment is compromised by domestic and other forms of violence, confusion can arise from the ambiguity of a place of safety becoming a place of violence. This is in line with Structured Family Systems Theory that describes dysfunctional families as a root cause for mental health difficulties and acting out behaviour amongst adolescents (Carr, 1999). This dissonance is compounded by the credible threats to safety and violence that young people traverse and experience in their communities in their daily lives. While one in six South Africans suffer from anxiety, depression, or substance use problems, adolescents do not feel safe disclosing abuse or seeking help, despite their knowledge of victim abuse services (Meinck et al., 2017).

These challenges are reflected in studies by Burnett (1998), Parkes (2007a), Parkes (2007b), and Ramphele (1997), which highlight the impact of oppression instituted by colonialism and apartheid on social behaviour. The high levels of violent crimes in South Africa can be attributed to structural violence endorsed by the previous apartheid regime to control the majority 'Black' population (Parkes, 2007a; Parkes, 2007b; Ramphele, 1997; Swart, 1997). Structural violence can manifest in multiple forms (Hamber, 2000; South African Police Service, 2001) that affect social institutions, including basic human rights and dignity, the family, religion, education, and economics. In these institutions, predominantly women and children are exposed to the cycle of violence (Aysen \& Nieuwoudt, 1992; Klassen, 1990). Through the brutal response of the apartheid institution on those oppressed, violence has become embedded in children's lives. This culture of violence has created an intergenerational legacy where victims become susceptible to being perpetrators of horizontal violence in their environments (Bulhan, 1985; Ramphele, 1997). The exposure to violence while not exclusive to, predominantly occurs in impoverished communities (Dawes \& Donald, 1994; Reynolds, 1989; World Bank, 1995). This was evidenced in findings across studies in the review, and highlighted by the recurring themes and discourses in the studies that link the cause of low SES conditions of these communities to the consequences of apartheid (see du Plessis et al., 2015; Hallman et al., 2015; Isaacs \& Savahl, 2014; Kaminer et al., 2013a; Khan et al., 2016).

With the fall of apartheid and the advent of the new political dispensation in South Africa, the Bill of Rights developed as the foundation of democracy. Embedded in the Bill of Rights is "the right to life, the right to freedom and security of the person, and the right to bodily and psychological integrity" (The Bill of Rights, 1996, p.6) for all citizens. Enshrined in the United Nations Convention on the Rights of the Child (UNCRC) is the protection of children from all forms of 
violence (United Nations, 2015), thus the protection of children is paramount. However, the violent landscape of South African society reflects the challenges of maintaining children's safety and protection, despite the resolution of various national and international laws. In the first national study of child homicide conducted by Mathews et al. (2013) in South Africa, it was found that the child homicide rate is more than double the global estimate with homicide involving rape mainly affecting girls. The disproportionately high child homicide rate motivated by sexual assault is indicative of the pervasiveness of sexual violence. This is linked to the belief of hegemonic masculinity and the power that males exert over females (Mathews et al., 2013).

\subsection{Gender and Sexual-Based Violence}

Of the three themes that emerged, gender and sexual-based violence yielded the least studies. Despite the severity and increase in gender and sexual-based violence, there is a lack of empirical studies seeking to understand the source of this violence in particular, and the increasing use of violence in general. Furthermore, the study by Gordon and Collins (2013) reflected the ubiquitous nature of violence in female adolescent lives. Living in constant fear of physical and sexual violence, they were expected to tolerate and cope with GBV instituted by culturally (Mosavel et al., 2011) and socially accepted male hegemonic authoritarianism (Gordon \& Collins, 2013). These findings are supported by studies reporting that South Africa has the highest rates of recorded rape and sexual violence in the world (Haffejee, 2006; Gordon \& Collins, 2013; Petersen et al., 2005). A study by the Medical Research Council (MRC, 2009) found that $37.4 \%$ of South African men admitted to committing a rape and $25.3 \%$ of women reported to having been raped (Rasool, 2017). Haffejee (2006) further articulated that adolescents expressed fear, feelings of hopelessness, discouragement, defeat, and an inevitability of experiencing an abusive relationship that they likely would have to face on their own given inadequate social support. Without this kind of support, adolescents are not able to receive assistance when they are confronted with situations that cause them distress (Barrera, 1986).

Research by Petersen et al. (2005) elucidated the factors that influence violence, foregrounding the centrality of the historical context and socio-economic conditions in South Africa. Within the family, male patriarchy and power were made dominant through the structures of apartheid (Campbell, 1992). Under this form of oppression, a culture of 'acceptable' violence developed in exacting discipline, exerting influence and dominance, and resolving disputes (Simpson, 1991). The erosion of Black African masculinity became compromised to a point of crisis (Campbell, 1992; Lindegger \& Durrheim, 2001). After the abolition of apartheid in 1994, the constitution of South Africa legislated equality of women in society (Morrell, 2001), which inadvertently exacerbated the erosion of traditional concepts of Black African masculinity (Petersen et al., 2005). Without targeted interventions to assist men to cope with these developments (Lindegger \& Durrheim, 2001), disenfranchised males used GBV to reclaim their power over women (Petersen et al., 2005). As can be seen in South African society, it is commonplace 
for men to coerce, control, and enforce obedience on women and girls by using various forms of violence (Wood \& Jewkes, 2001).

Thus, owing to the ubiquitous nature of GBV and oppression, the United Nations formulated the Sustainable Development Goals (SDGs), "a universal call to action to end poverty, protect the planet and ensure that all people enjoy peace and prosperity by 2030" (United Nations, 2015). In this mandate, gender equality (Goal 5) is focused on eradicating female genital mutilation; early marriage; legal discrimination; addressing unfair social norms and attitudes; decision-making on sexual and reproductive issues and low levels of political participation. A recent SDG progress report (2019) indicates that insufficient progress on structural issues undermines the ability to achieve SDG 5 (United Nations, 2015).

In South Africa, legislation has been implemented to target GBV and the Justice, Crime Prevention and Security Cluster has adopted a zero-tolerance stance to GBV. The Protection from Harassment Act, 2011 (Act 17 of 2011) (Department of Justice, 1996) constitutes the "first specific legislation to address sexual harassment in the Southern African Development Community (SADC) region" (Department of Justice and Correctional Services, 2019, p. 12). Notably however, the incidence of gender and sexual-based violence, and violence in general, in South Africa continues to rise. In sum, stringent enforcement of the law must be paired with educational and supportive intervention strategies to reduce, eliminate, and eradicate violent behaviour.

\subsection{Interpersonal and School Violence}

Youth and adolescents in schools are not immune to the cycle of violence. A study by Ncontsa and Shumba (2013) found that the most prevalent forms of violence in schools were bullying, vandalism, gangsterism, indiscipline, intolerance, and corporal punishment. Most students expressed that older male students were often the perpetrators of violence. Diminished school enjoyment was attributed to exposure to multiple forms of violence at school (Ncontsa \& Shumba, 2013). Although corporal punishment is illegal in South African schools, students expressed their humiliation, resentment, and feelings of helplessness when physically punished by school educators or the school principal (Burnett, 1998; Mampane et al., 2014; Ncontsa \& Shumba, 2013). Studies have found that corporal punishment and punitive teaching styles perpetuate a culture of violence among children (Burnett, 1998; Harber, 2004; Steyn \& Naicker, 2007). Coupled with poor role-modelling and poor parenting, continuous exposure to violence develops negative learnt behaviours for adolescents by using aggression when dealing with conflict and challenging life events (Khan, 2008). School learners in low SES communities are more susceptible to violence as they lack agency when subjected to corporal punishment (Burnett, 1998; Ngqela $\&$ Lewis, 2012). School violence is a product of the community's social dysfunction, (Steyn \& Naicker 2007) and by extension, that society's behaviour is reflective of the communities and the families therein (Ngqela \& Lewis, 2012). Further, children reared in violent homes have a higher probability of internalising violence as patterns of behaviour that manifest in current and future interpersonal relationships (Bandura, 1973). Thus, laws are constituted to develop a framework within 
which children and parents/guardians function. The UNCRC seeks to ensure that "every child has the right to survival, protection, and education" (United Nations, 1989, p.1). The Children's Act 38 of 2005 further seeks to imbue the best interest of the child by affording children the right to participate in matters affecting them, care and protection, defined parental responsibilities, and social, cultural, and religious developmental opportunities under the constitution of South Africa (The Children's Act, 2005).

As children are socialised, they are set on a path of 'becoming'. They learn patterns of behaviour from those in their environment (Khan, 2008). Social Learning theorists posit that these patterns of behaviour evolve from intergenerational relationships (Kubeka, 2008). Apartheid is a legacy that traumatically etched an indelible mark on the psyche of the people of South Africa (Mampane et al., 2014). This legacy of intergenerational trauma has not been dealt with in an appropriate way (Lindegger \& Durrheim, 2001), which is evident in the overt violent interpersonal relationships displayed by people in South Africa, with the majority of incidence perpetrated in low SES communities (Mampane et al., 2014; Ncontsa \& Shumba, 2013; Savahl et al., 2013; Swartz \& Scott, 2014). Youth and adolescents are not only exposed to and experience violence, but also become the perpetrators of violence through learnt behaviours (Bulhan, 1985; Ramphele, 1997). Through the process of learnt violent behaviour, the cycle is perpetuated and strengthened. To break the cycle of violence, a multifaceted comprehensive approach is paramount.

As can be seen, the three themes are not mutually exclusive but inextricably linked. There is a defined relation between and within the themes. The exposure to and experience of violence has a profound and destructive effect on youth and adolescents' interpersonal relationships (Hertweck et al., 2010), which was evident in the various studies identified. Thus, when considering the context of South Africa, the impact of oppression and structural violence by colonialism and apartheid caused the marginalisation of most of the South African Black population. This in turn contributed significantly to the current experiences of poverty in low SES communities (Dawes \& Donald, 1994; Reynolds, 1989; World Bank, 1995). With the subjugation of the South African Black population, structural violence was used to dominate and ingrain patterns of relations to control the masses by the minority. As individuals were born and socialised into this oppressive structure, either as victim or perpetrator, the cycle of violence perpetuated through structural violence, institutional violence, and personal violence across generations. With structural violence enacted by the oppressors, it became increasingly challenging to escape the oppressive nature of subjugation. Collective retaliatory action by the oppressed was considered vital in attaining their freedom from structural oppressive violence (Bulhan, 1985; Freire, 2000). However, when the oppressor abdicates their power and hands it to the oppressed as a 'sign of generosity', the oppressed are susceptible to falling victim to identification with the oppressor and may become the oppressed and play out their ascribed roles (Freire, 2000). Thus, structural violence meted out by oppressive regimes become internalised by the victims who in turn enact horizontal violence onto those around them (Bulhan, 1985). This then creates a culture of violence, which is prevalent in South African society, where the intergenerational 
legacy of colonialism and apartheid has created the perpetuation of horizontal violence (Bulhan, 1985; Ramphele, 1997).

\section{Conclusion, Limitations, and Recommendations}

The current review contributes to the literature by focusing on the and effects of post-apartheid violence by synthesising the empirical research on adolescents and young adults' perceptions and perspectives. Through understanding these mechanisms of intergenerational violence, it affords insights into the patterns of behaviour of adolescents as well as employing remedial action needed to ameliorate the apparent challenges. The findings of this study can be used to guide and inform future research studies can be guided by the findings of the current study, reform social policies related to youth and adolescents' experiences of violence, and how these policies pertaining to managing and reducing violence are enacted. It could afford more security to youth and adolescents in the implementation of such policies, which would have a direct effect on their protection from the deleterious negative outcomes of violence.

Although there has been a marked shift in focus from an adult-centred approach on youth and adolescents' perspectives of violence to a more youth-centred approach, few studies have asked young people directly about their perceived experience of violence.

\subsection{Limitations}

Only English-language studies and peer-reviewed publications were considered. As grey literature and commissioned reports were excluded, an important component of unpublished literature may have been missed.

\subsection{Recommendations}

More research is needed at grassroots levels to gain a clearer perspective on how children, adolescents, and young people understand violence in general, and different types of violence from diverse age ranges across various SES contexts in the different provinces of South Africa, using various methodological frameworks. Of equal importance, is the need for remedial action through educational social outreach programmes, which can contribute to a more informed understanding of the social dynamics that youth encounter owing to the various forms of violence. These interventions must be inclusively actioned using a bottom-up and top-down approach, through collaboration with civil society and local and national governmental structures, working within equitable partnerships to attain redress. In conjunction with mental health professionals, educators, and appropriately trained support staff at schools, working groups can be formed to provide a platform for youth 
and adolescents to identify challenges and inclusively identify ways of overcoming them with children and young people.

Supplementary Information The online version contains supplementary material available at https://doi. org/10.1007/s12187-021-09890-5.

\section{Declarations}

Conflict of Interest The authors declare no conflict of interest.

\section{References}

Adams, S., Savahl, S., \& Fattore, T. (2017). Children's representations of nature using photovoice and community mapping: Perspectives from South Africa. International Journal of Qualitative Studies on Health and Well-being, 12(1), 1-22. https://doi.org/10.1080/17482631.2017.1333900

Adams, S., Savahl, S., \& Florence, M. (2019). Considering the natural environment in the creation of child-friendly cities: Implications for children's subjective well-being. Child Indicators Research, 12, 545-567. https://doi.org/10.1007/s12187-018-9531-x

Arai, L., Britten, N., Popay, J., Roberts, H., Petticrew, M., Rodgers, M., \& Sowden, A. (2007). Testing methodological developments in the conduct of narrative synthesis: A demonstration review of research on the implementation of smoke alarm interventions. Evidence \& Policy: A Journal of Research, Debate and Practice, 3(3), 361-383.

Aysen, N. B., \& Nieuwoudt, J. (1992). Attitudes of Black senior primary school pupils to the 1991 Soweto township violence and unrest. Unisa Psychologia, 19(1), 24-29.

Bandura, A. (1973). Aggression: A social learning analysis. Prentice-Hall.

Barrera, M. (1986). Distinctions between social support concepts, measures, and models. American Journal of Community Psychology, 14(4), 413-445.

Benninger, E., \& Savahl, S. (2016). A systematic review of children's construction of the self: Implications for children's subjective well-being. Child Indicators Research, 10(2), 545-569. https://doi. org/10.1007/s12187-016-9382-2

Boucher, M. (1991). The Cape under the Dutch East India Company. In T. Cameron (Ed.), A New Illustrated History of South Africa (2nd ed.) (pp. 61-62). Southern Book Publishers.

Braun, V., \& Clarke, V. (2006). Using Thematic Analysis in Psychology. Qualitative Research in Psychology, 3(2), 77-101.

Bredenkamp, H. C. (1991). Hunter-gatherers, herders, and farmers: The origin of the Southern African Khoisan communities. In T. Cameron (Ed.), A New Illustrated History of South Africa. Southern Book Publishers.

Bulhan, H. A. (1985). Frantz Fanon and the psychology of oppression. Plenum Press.

Burnett, C. (1998). School violence in an impoverished South African community. Child Abuse \& Neglect, 22(8), 789-795.

Campbell, C. (1992). Learning to kill? Masculinity, the family and violence in Natal. Journal of Southern African Studies, 18(3), 614-628.

Carr, A. (1999). The Handbook of Child and Adolescent Clinical Psychology: A Contextual Approach. Routledge.

Charmaz, K. (2006). Constructing Grounded Theory: A Practical Guide through Qualitative Analysis. SAGE Publications.

Dawes, A., \& Donald, D. (Eds.). (1994). Childhood \& adversity: Psychological perspectives from South African research. David Philip Publishers.

Denzin, N. K. (1989). Interpretive Interactionism. SAGE Publications.

Department of Justice and Correctional Services. (2019). Justice System: Legislation and policies. https:// www.gov.za/about-government/legislation-and-policies. Retrieved June 2019. 
du Plessis, B., Kaminer, D., Hardy, A., \& Benjamin, A. (2015). The contribution of different forms of violence exposure to internalizing and externalizing symptoms among young South African adolescents. Child Abuse \& Neglect, 45, 80-89. https://doi.org/10.1016/j.chiabu.2015.02.021

Finkelhor, D., Ormrod, R. K., \& Turner, H. A. (2007). Polyvictimizationand trauma in a national longitudinal cohort. Development and Psychopathology, 19, 149-166.

Freire, P. (2000). Pedagogy of the oppressed (30 ${ }^{\text {th }}$ anniversary ed.). Continuum.

Gardner, F., Waller, R., Maughan, B., Cluver, L., \& Boyes, M. (2015). What are the risk factors for antisocial behavior among low-income youth in Cape Town? Social Development, 24(4), 798-814. https://doi.org/10.1111/sode.12127

Glaser, B., and Strauss, A. (1965). The discovery of Grounded Theory: Strategies for qualitative research. Aldine Transactions.

Gordon, S. F., \& Collins, A. (2013). 'We face rape. We face all things': Understandings of gender-based violence amongst female students at a South African university. African Safety Promotions Journal, 11(2), 93-106.

Haffejee S. (2006). Waiting opportunities: Adolescent girls' experiences of gender-based violence at schools. Centre for the Study of Violence and Reconciliation's Gender-based Violence programme. http://www.csvr.org.za/papers/paphaff.htm. Retrieved July 2018.

Hallman, K. K., Kenworthy, N. J., Diers, J., Swan, N., \& Devnarain, B. (2015). The shrinking world of girls at puberty: Violence and gender-divergent access to the public sphere among adolescents in South Africa. Global Public Health, 10(3), 279-295.

Hamber, B. (2000). Have no doubt it is fear in the land: An exploration of the continuing cycles of violence in South Africa. Southern African Journal of Child and Adolescent Mental Health, 12(1), $5-18$.

Harber, C. (2004). Schooling as violence: How schools harm pupils and societies. Routledge Falmer.

Heeralal, P. J. H. (2014). Adolescents' perception of rape in South Africa. Journal of Social Sciences, 39(1), 121-124.

Henrich, C. C., Schwab-Stone, M., Fanti, K., Jones, S. M., \& Ruchkin, V. (2004). The association of community violence exposure with middle-school achievement: A prospective study. Journal of Applied Developmental Psychology, 25(3), 327-348. https://doi.org/10.1016/j.appdev.2004.04.004

Hertweck, S. P., Ziegler, C. H., \& Logsdon, M. C. (2010). Outcome of exposure to community violence in female adolescents. Journal of Paediatric and Adolescent Gynaecology, 23(4), 202-208.

Hobsbawm, E. (1998). Uncommon People: Resistance, Rebellion and Jazz. Weidenfeld \& Nicolson.

Isaacs, S. A., \& Savahl, S. (2014). A qualitative inquiry investigating adolescents' sense of hope within a context of violence in a disadvantaged community in Cape Town. Journal of Youth Studies, 17(2), 269-278. https://doi.org/10.1080/13676261.2013.815703

Kaminer, D., du Plessis, B., Hardy, A., \& Benjamin, A. (2013b). Exposure to violence across multiple sites among young South African adolescents. Peace and Conflict: Journal of Peace Psychology, 19(2), 112-124. https://doi.org/10.1037/a0032487

Kaminer, D., Hardy, A., Heath, K., Mosdell, J., \& Bawa, U. (2013a). Gender patterns in the contribution of different types of violence to posttraumatic stress symptoms among South African urban youth. Child Abuse \& Neglect, 37(5), 320-330. https://doi.org/10.1016/j.chiabu.2012.12.011

Khan, F. (2008). Building school safety: The Hlayiseka Project - A whole school approach. Centre for Justice and Crime Prevention (Paper No 6.). http://www.cjcp.org.za/publications.html (Retrieved on 10 February 2020).

Khan, G., Savahl, S., \& Isaacs, S. (2016). Adolescents' perceptions of the 'substance use- violence nexus': A South African perspective. Journal of Youth Studies, 19(9), 1290-1301. https://doi.org/ 10.1080/13676261.2016.1145635

Khan, S., Kunz, R., Kleijnen, J., \& Antes, G. (2003). Five steps to conducting a systematic review. Journal of the Royal Society of Medicine, 96(3), 118-121.

Klaasen, E. (1990). The impact of violence on children. The South African Outlook, 120, 2-3.

Kubeka, A. M. (2008). Exposure to violence at home: A qualitative exploration of experiences and perceptions of black adolescents in South Africa. South African Review of Sociology, 39(2), 282-300. https://doi.org/10.1080/21528586.2008.10425092

Leibovici, L., \& Reeves, D. (2005). Systematic reviews and meta-analyses in the Journal of Antimicrobial Chemotherapy. Journal of Antimicrobial Chemotherapy, 56(5), 803-804. https://doi.org/10.1093/ jac/dki340 
Lindegger, G., \& Durrheim, K. (2001). Men, HIV/AIDS and the crisis of masculinity. In C. Stones (Ed.), Socio-political and psychological perspectives in South Africa (pp. 229-250). Nova Science Publishers.

Long, A. F., \& Godfrey, M. (2004). An evaluation tool to assess the quality of qualitative research studies. International Journal of Social Research Methodology Theory and Practice, 7(2), 181-196. https://doi.org/10.1080/1364557032000045302

Long, A.F., Godfrey, M., Randall, T., Brettle, A.J., \& Grant, M.J. (2002). Developing evidence based social care policy and practice. Part 3: Feasibility of undertaking systematic reviews in social care. Nuffield Institute for Health.

Mampane, R., Ebersohn, L., Cherrington, A., \& Moen, M. (2014). Adolescent' views on the power of violence in a rural school in South Africa. Journal of Asian and African Studies, 49(6), 733-745.

Manyema, M., Norris, S. A., Said-Mohamed, R., Tollman, S. T., Twine, R., Kahn, K., \& Richter, L. M. (2018). The associations between interpersonal violence and psychological distress among rural and urban young women in South Africa. Health \& Place, 51, 97-106. https://doi.org/10.1016/j.healt hplace.2018.03.003

Mathews, S., Abrahams, N., Jewkes, R., Martin, L. J., \& Lombard, C. (2013). The epidemiology of child homicides in South Africa. Injury Prevention., 18(1), A183-A184. https://doi.org/10.1136/injur yprev-2012-040590q.20

Meinck, F., Cluver, L., Loening-Voysey, H., Bray, R., Doubt, J., Casale, M., \& Sherr, L. (2017). Disclosure of physical, emotional and sexual child abuse, help-seeking and access to abuse response services in two South African Provinces. Psychology, Health \& Medicine, 22(1), 94-106. https://doi. org/10.1080/13548506.2016.1271950

Moher, D., Liberati, A., Tetzlaff, J., Altman, D. G., \& The PRISMA Group. (2009). Preferred Reporting Items for Systematic Reviews and Meta-Analyses: The PRISMA Statement. PLoS Medicine, 6(7), e1000097. https://doi.org/10.1371/journal.pmed1000097

Moher, D., Shamseer, L., Clarke, M., Ghersi, D., Liberati, A., Petticrew, M., Shekelle, P., \& Stewart, L. A. (2015). Preferred Reporting Items for Systematic Review and Meta-Analysis Protocols (PRISMA-P) 2015 statement. Systematic Reviews, 4(1), 1. https://doi.org/10.1186/2046-4053-4-1

Morrell, R. (2001). The times of change: Men and masculinity in South Africa. In R. Morrell (Ed.), Changing men in southern Africa (pp. 3-37). Zed Books.

Mosavel, M., Ahmed, R., \& Simon, C. (2011). Perceptions of gender-based violence among South African youth: Implications for health promotion interventions. Health Promotion International, 27(3), 23-30. https://doi.org/10.1093/heapro/dar041

MRC-UNISA. (2010). A profile of fatal injuries in South Africa: The National Injury Mortality Surveillance System. Medical Research Council.

National Youth Commission Act. (1996). Government Gazette. (No. 19).

Ncontsa, V. N., \& Shumba, A. (2013). The nature, causes, and effects of school violence in South African high schools. South African. Journal of Education, 33(3), 1-15. https://doi.org/10.15700/20150 3070802

Neser, J. J. (2006). The prevalence of school violence and the impact on victimised learners: An exploratory study. Child Abuse Research in South Africa, 7(1), 31-47.

Ngqela, N., \& Lewis, A. (2012). Exploring adolescent learners' experiences of school violence in a township high School. Child Abuse Research: A South African Journal, 13(1), 87-97.

Oskin, D. L. (1996). Impact of community violence exposure on children's hope. Annual meeting of the American Psychological Association. Canada.

Parkes, J. (2007a). Tensions and troubles in young people's talk about safety and danger in a violent neighbourhood. Journal of Youth Studies, 10(1), 117-137. https://doi.org/10.1080/1367626060 0983676

Parkes, J. (2007b). The multiple meanings of violence: Children's talk about life in a South African neighbourhood. Childhood, 14(4), 401-414. https://doi.org/10.1177/0907568207081848

Petersen, C., Grobler, H., \& Botha, K. (2017). Adolescent experiences of sense of self in the context of family violence in a South African community. Journal of Psychology in Africa, 27(2), 180-184. https://doi.org/10.1080/14330237.2017.1303118

Petersen, I., Bhana, A., \& McKay, M. (2005). Sexual violence and youth in South Africa: The need for community-based prevention interventions. Child Abuse \& Neglect, 29(11), 1233-1248. https://doi. org/10.1016/j.chiabu.2005.02.012 
Popay, J., Roberts, H., Sowden, A., Petticrew, M., Arai, L., Rodgers, M., Britten, N., Roen, K., \& Duffy, S. (2006). Guidance on the conduct of narrative synthesis in systematic reviews: A product from the ESRC Methods Programme. Lancaster University. https://doi.org/10.13140/2.1.1018.4643

Ramphele, M. A. (1997). Adolescents and violence: 'Adults are cruel, they just beat, beat, beat!'. Social Science \& Medicine, Elsevier, 45(8), 1189-1197.

Rasool, S. (2017). Adolescent reports of experiencing gender-based violence: Findings from a cross-sectional survey from schools in a South African city. Gender and Behaviour, 15(2), 9109-9122.

Reynolds, P. (1989). Childhood in crossroads. David Philip Publishers.

Richter, L. M., Mathews, S., Nonterah, E., \& Masilela, L. A. (2018). A longitudinal perspective on boys as victims of childhood sexual abuse in South Africa: Consequences for adult mental health. Child Abuse \& Neglect, 84, 1-10. https://doi.org/10.1016/j.chiabu.2018.07.016

Sadock, B. J., Sadock, V. A., \& Ruiz, P. (2015). Kaplan \& Sadock's synopsis of psychiatry: Behavioral sciences/clinical psychiatry (11th ed.). Wolter Kluwer/Lippincott Williams \& Wilkins.

Sathiparsad, R. (2005). 'It is better to beat her': Male youth in rural KwaZulu-Natal speak on violence in relationships. Empowering Women for Gender Equity, 19(66), 79-88.

Savahl, S., Adams, S., Benninger, E., Florence, M., Jackson, K., Manuel, D., Mpilo, M., Bawa, U., \& Isobell, D. (2019). Researching Children's Subjective Well-Being in South Africa: Considerations for Method, Theory and Social Policy (pp. 407-430). In I. Eloff, Quality-of-life in African societies. Springer.

Savahl, S., Casas, F., \& Adams, S. (2016). Validation of the children's hope scale amongst a sample of adolescents in the Western Cape region of South Africa. Child Indicators Research, 9(3), 701-713. https://doi.org/10.1007/s12187-015-9334-2

Savahl, S., Isaacs, S., Adams, S., Carels, C., \& September, R. (2013). An exploration into the impact of exposure to community violence and hope on children's perceptions of wellbeing: A South African perspective. Child Indicators Research, 6(3), 579-592.

Savahl, S., Tiliouine, H., Casas, F., Adams, S., Mekonen, Y., Dejene, N., Benninger, E., \& Witten, H. (2017). Children's subjective well-being in Africa: A comparative analysis across three countries. Children and Youth Services Review, 80(C), 31-40. https://doi.org/10.1016/j.childyouth.2017.06. 063

Scorgie, F., Baron, D., Stadler, J., Venables, E., Brahmbhatt, H., Mmari, K., \& Delany-Moretlwe, S. (2017). From fear to resilience: Adolescents' experiences of violence in inner-city Johannesburg. South Africa. BMC Public Health, 17(3), 441. https://doi.org/10.1186/s12889-017-4349-x

Selenga, M., \& Jooste, K. (2015). The experience of youth victims of physical violence attending a community health centre: A phenomenological study. Africa Journal of Nursing and Midwifery, 17(1), 29-42.

September, R., \& Savahl, S. (2009). Children's perspectives on child well-being. The Social Work Practitioner-Researcher, 21(1), 23-40.

Shields, N., Nadasen, K., \& Pierce, L. (2008). The effects of community violence on children in Cape Town. South Africa. Child Abuse \& Neglect, 32(5), 589-601. https://doi.org/10.1016/j.chiabu.2007. 07.010

Shields, N., Nadasen, K., \& Pierce, L. (2009). A comparison of the effects of witnessing community violence and direct victimization among children in Cape Town, South Africa. Journal of Interpersonal Violence, 24(7), 1192-1208. https://doi.org/10.1177/0886260508322184

Simpson, G. (1991). Explaining sexual violence: Some background factors in the current socio-political context. Unpublished report, Center for the Study of Violence.

South African Police Service. (2001). The reported serious crime situation in South Africa for the period January - September 2001. Crime Information Analysis Centre.

South African Police Service. (2019). Annual Crime Report 2018/2019. SAPS Corporate Communication and Liaison.

South African Police Service. (2020). Annual Crime Report 2019/2020. SAPS Corporate Communication and Liaison.

Statistics South Africa. (2020). Victims of Crime Survey 2019/2020. Statistics South Africa.

Steyn, J., \& Naicker, M. (2007). Learner, educator and community views on school safety at Strelitzia Secondary School. Acta Criminologica, 20(3), 1-20.

Sui, X., Massar, K., Kessels, L. T. E., Reddy, P. S., Ruiter, R. A. C., \& Kathy Sanders-Phillips, K. (2018). Violence Exposure in South African Adolescents: Differential and Cumulative Effects on Psychological Functioning. Journal of Interpersonal Violence, 36(9-10), 4084-4110. 
Swart, P. (1997). The past is an important reason for the cause of violence in South Africa (translation). Rapport, 22 June, p. 13

Swartz, S., \& Scott, D. (2014). The rules of violence: A perspective from youth living in South African townships. Journal of Youth Studies, 17(3), 324-342. https://doi.org/10.1080/13676261.2013. 815699

The Bill of Rights of the Constitution of the Republic of South Africa. (1996). Government Gazette. (No. 17678).

The Children's Act 38 of the Constitution of the Republic of South African. (2005). Government Gazette. (No. 28944).

Ungar, M., \& Perry, B. D. (2012). Violence, trauma, and resilience. In R. Alaggia \& C. Vine (Eds.), Cruel but not unusual: Violence in Canadian families (2nd ed.). Wilfrid Laurier University Press.

United Nations. (1989). Convention on the Rights of the Child. Treaty Series, 1577, 3. https://www.savet hechildren.org.uk/what-we-do/childrens-rights/united-nations-convention-of-the-rights-of-the-child. Retrieved January 2018.

United Nations. (2015). Transforming our world: The 2030 agenda for sustainable development. http:// www.un.org/ga/search/view_doc.asp?symbol=A/RES/70/1\&Lang=E. Retrieved December 2020.

Vaismoradi, M., Turunen, H., \& Bondas, T. (2013). Content analysis and thematic analysis: Implications for conducting a qualitative descriptive study. Nursing \& Health Sciences, 15(3), 398-405. https:// doi.org/10.1111/nhs.12048

Ward, C. L., Artz, L., Leoschut, L., Kassanjee, R., \& Burton, P. (2018). Sexual violence against children in South Africa: a nationally representative cross-sectional study of prevalence and correlates. Lancet Global Health, 6(4), e460-e468.

Ward, C. L., Flisher, A. J., Zissis, M., \& Lombard, C. (2001). Exposure to violence and its relationship to psychopathology in adolescents. Injury Prevention, 7(4), 297-301.

Wood, K., \& Jewkes, R. (2001). 'Dangerous' love. Reflections on violence among Xhosa township youth. In R. Morrell (Ed.), Changing men in southern Africa (pp. 317-336). Zed Books.

Wood, K., Maforah, F., \& Jewkes, R. (1998). 'He forced me to love him': Putting violence on adolescent sexual health agendas. Social Science \& Medicine, 47(2), 233-242.

World Bank. (1995). Key indicators of poverty in South Africa. An analysis prepared for the Office of the Reconstruction and Development Program by the World Bank, based on the South African Living Standards Survey. Southern Africa Labor and Development Research Unit (SALDRU), University of Cape Town. Unpublished document.

World Health Organization, Violence Prevention Alliance. (2019). Definition and typology of violence. https://www.who.int/violenceprevention/approach/definition/en/. Retrieved May 2019.

Publisher's Note Springer Nature remains neutral with regard to jurisdictional claims in published maps and institutional affiliations. 